\title{
Tumor volume as a prognostic factor of locally advanced laryngeal cancer
}

\author{
Natália Martins Magacho de Andrade ${ }^{1}$ (1) $\cdot$ Rogério Aparecido Dedivitis $^{1} \cdot$ Daniel Marin Ramos ${ }^{2}$. \\ Leandro Luongo Matos ${ }^{1,2} \cdot$ Marcio Ricardo Taveira Garcia ${ }^{3} \cdot$ Gustavo Gonçalves Conti $^{3} \cdot$ Luiz Paulo Kowalski $^{4}$
}

Received: 28 February 2021 / Accepted: 4 March 2021 / Published online: 11 March 2021

(c) The Author(s), under exclusive licence to Springer-Verlag GmbH Germany, part of Springer Nature 2021

Keywords Laryngeal neoplasms $\cdot$ Imaging $\cdot$ Three-dimensional $\cdot$ Neoplasm staging $\cdot$ Prognosis $\cdot$ Survival

Dear Dr. Luo,

The authors would like to thank you for your observations. The majority of these points were observed by the reviewers and properly discussed in the manuscript. Despite we enrolled the large retrospective cohort of surgically treated pT3 and pT4 larynx cancer patients, the sample still small for any further most robust statistical analyses. Based on that, we decided to select only variables with $P<0.1$ at univariate analyses to be tested as possible confounders at multivariate analyses. The inclusion of many variables for multiple comparisons in a relatively small sample could lead to a much less accurate statistical model at the regression. If carefully observed, if the cutoff of $P<0.2$, what is the most used in medical literature, was adopted, only one additional variable (smoking) should have been included and only for disease-free survival endpoint. Moreover, we did just an exploratory (subgroup) analysis with the pT4 group, the largest amongst the enrolled patients. Because of that, we also decided not to perform multivariate analysis for

This reply refers to the comment available online at https://doi. org/10.1007/s00405-020-06523-5.

Natália Martins Magacho de Andrade

natmagacho@hotmail.com

1 Department of Head and Neck Surgery, Instituto Central, Disciplina de Cirurgia de Cabeça e PescoçoAvenida Doutor Enéas de Carvalho Aguiar, 255, University of Sao Paulo Medical School, $8^{\circ}$ andar. Cerqueira César, São Paulo ZIP CODE: 05403-000, Brazil

2 Instituto do Câncer do Estado de São Paulo (ICESP), São Paulo, Brazil

3 Department of Radiology, Instituto do Câncer do Estado de São Paulo (ICESP), São Paulo, Brazil

4 Department of Head and Neck Surgery, University of Sao Paulo Medical School, São Paulo, Brazil these group, exactly because of the risk of even more loss of statistical power. As well and for the same reason, we did not perform any propensity score analyzes. A retrospective study like ours has the intrinsic limitation of information bias risk, especially for the time of recurrence, and also is suitable for more type II error. This could be an explanation for why the tumor volume for larynx cancer is still been studied as a prognostic factor in different institutions with different results. Probably a multicentric study or metanalyses could better answer this question. Finally, we properly discussed that "TV can be a promising prognostic factor for these patients, probably in a large cohort", demonstrating the authors' commitment to the transparency of the limitations of our results.

Author contributions All authors contributed to the study's conception and design. Material preparation, data collection and analysis were performed by NA, DR, RD and GC. The first draft of the manuscript was written by NA and all authors commented on previous versions of the manuscript. All authors read and approved the final manuscript.

Funding No financial support funds were used in this study.

\section{Declarations}

Conflict of interest The authors don't have any conflicts of interest.

Publisher's Note Springer Nature remains neutral with regard to jurisdictional claims in published maps and institutional affiliations. 